\title{
Long term continuous domiciliary oxygen therapy by transtracheal catheter
}

\author{
D A Walsh, J R Govan
}

\begin{abstract}
Long term continuous oxygen therapy improves prognosis in patients with hypoxaemic chronic airflow limitation. Transtracheal delivery of oxygen permits adequate oxygenation of such patients at lower flow rates than are required for delivery by nasal cannulas, thus increasing the time for which portable oxygen cylinders can be used and improving the efficacy of domiciliary oxygen concentrators in patients with refractory hypoxaemia. In a study of the long term acceptability and risks of transtracheal oxygen in 37 patients, with a total follow up of $\mathbf{5 9 5}$ patient-months, most patients reported symptomatic benefit and four have used transtracheal oxygen successfully for more than four years. Problems have included surgical emphysema (4 patients), catheter fracture (9), local infection (34), and catheter dislodgement (21); but these have been relatively infrequent and in general have not caused important clinical problems. Transtracheal oxygen therapy was discontinued in 10 patients before death for various reasons, including infection ( 2 patients), catheter fracture (1), and surgical emphysema (1). Accumulation of mucus balls has not been a problem. It is concluded that transtracheal oxygen therapy is a safe and acceptable alternative to nasal cannulas in well motivated patients with hypoxaemia due to chronic airflow limitation who are keen to pursue an active life.
\end{abstract}

Long term continuous oxygen therapy for at least 15 hours a day has been shown to prolong life in patients with severe hypoxaemia due to chronic airflow limitation. ${ }^{12}$ It may also be of symptomatic benefit in patients with chronic hypoxaemia due to other lung diseases. ${ }^{3}$ Oxygen improves performance and reduces dyspnoea during exercise ${ }^{4}$ and improves measures of psychological function. ${ }^{5}$

Most patients receiving continuous domi-

Department of Respiratory Medicine, Harefield Hospital, Harefield, Middlesex D A Walsh J R Govan

Address for reprint requests: Dr J R Govan, Department of Respiratory Medicine, Harefield Hospital, Harefield, Middlesex UB9 6JH.

Accepted 5 March 1990 flow rates produced by concentrators. Portable oxygen can be provided in the form of compressed gas, but cylinders may last for only two hours with nasal cannulas before they need to be refilled, limiting the length of time that patients can be away from their concentrator. Some patients find nasal cannulas uncomfortable or cosmetically embarassing and this may adversely influence compliance.

Transtracheal oxygen delivery avoids many of these problems. ${ }^{6-12}$ Oxygen is delivered through a catheter directly into the trachea, thus reducing wastage to the atmosphere and permitting a $50 \%$ reduction in oxygen flow rate. Portable cylinders can be used for longer periods and higher arterial oxygen tensions $\left(\mathrm{PaO}_{2}\right)$ can be produced with the flow rates permitted by an oxygen concentrator. ${ }^{13}$ The rate of complications and the acceptability to patients appear to vary according to the system used. ${ }^{17}$ We report our long term experience with transtracheal oxygen therapy during the five years since it was first used at Harefield Hospital in 1984

\section{Methods}

We reviewed all patients who had had transtracheal catheters inserted at Harefield Hospital for continuous oxygen therapy. Case notes from Harefield Hospital and the patients' local hospitals were reviewed. In addition, a postal questionnaire was sent to the general practitioners inquiring about the patient's general wellbeing, duration of transtracheal oxygen use, complications, and any other problems that had occurred. Surviving patients were interviewed. This paper incorporates data from our previously reported early experience. ${ }^{10}$

Most patients satisfied established criteria for long term domiciliary oxygen therapy ${ }^{3}$ and in addition were motivated to pursue an active and independent life. One patient had refractory hypoxaemia $\left(\mathrm{PaO}_{2}\right.$ at rest $<8 \mathrm{kPa}$ with maximal inspired oxygen given by nasal cannulas).

Our method for the insertion of transtracheal catheters is based on that of Heimlich et $a l^{14}$ and has been described. ${ }^{11}$ In brief, a Teflon "intravenous" catheter (16G Angiocath, Deseret Medical Inc, Parke Davies, Utah) is secured in an inverted paediatric tracheostomy tube and inserted between the second and third tracheal rings. Oxygen is delivered initially at $0.25 \mathrm{1} / \mathrm{min}$ through the transtracheal catheter and the patient is observed in hospital overnight for any evidence of surgical emphysema. The flow rate is then increased to that required to maintain a resting $\mathrm{PaO}_{2}$ of at least $8 \mathrm{kPa}$. This is usually half the flow rate required with 
nasal cannulas. ${ }^{10}$ An experimental catheter was used for a short period in two patients but was found to be unsatisfactory (see below).

Baseline lung function, packed cell volume, and arterial blood gas tensions were recorded routinely when the patients were in a stable condition before they were accepted into the transtracheal programme. Lung volumes were measured by helium dilution. SEPCR normal values for lung function data were used. ${ }^{15}$

\section{Results}

Thirty seven patients ( 31 male) had transtracheal catheters inserted at Harefield Hospital for long term continuous oxygen therapy from February 1984 to July 1989 . The total follow up for transtracheal oxygen therapy has been 595 patient-months (mean 16, range 0-60 months per patient). Four patients have used transtracheal oxygen successfully for more than four years. Details of the patients before they started transtracheal oxygen therapy are given in table 1 .

The mean rate of oxygen delivery by transtracheal catheter required to maintain $\mathrm{aaO}_{2}$ at rest of at least $8 \mathrm{kPa}$ was $1.0(\mathrm{SD} 0.5) 1 / \mathrm{min}$. Resting arterial carbon dioxide tension $\left(\mathrm{PaCO}_{2}\right)$ tended to be higher when the $\mathrm{PaO}_{2}$ was improved to $8 \mathrm{kPa}$ or more than it was during the breathing of air (mean (SD) increase in $\mathrm{PaCO}_{2} 0.4(0.8) \mathrm{kPa} ; \mathrm{p}<0.002$, paired $t$ test). This small increase in $\mathrm{PaCO}_{2}$ was not, however, found to be clinically important.

Seven patients were known to be still alive in July 1989, and 26 had died since the beginning of the study. Of the 24 for whom the cause of death is known, $16(67 \%)$ died of respiratory causes, three of ischaemic heart disease, three of carcinoma of the bronchus, one of disseminated adenocarcinoma, and one of a ruptured aortic aneurysm. No deaths have been attributable to transtracheal oxygen therapy.

Complications have usually been minor and easily treated (table 2). Of the 10 episodes of surgical emphysema, most occurred within two days of catheter insertion or replacement,

Table 1 Details of the 37 patients before the start of transtracheal oxygen therapy

\begin{tabular}{|c|c|c|}
\hline Age (years) & $\begin{array}{c}\text { Mean } \\
66\end{array}$ & $\begin{array}{l}\text { Range } \\
46-81\end{array}$ \\
\hline Diagnosis & Number & $\%$ \\
\hline $\begin{array}{l}\text { Chronic airflow limitation } \\
\text { Fibrosing alveolitis }\end{array}$ & $\begin{array}{r}35 \\
2\end{array}$ & $\begin{array}{r}95 \\
5\end{array}$ \\
\hline 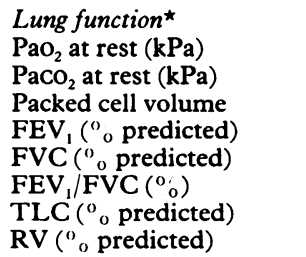 & $\begin{array}{c}\text { Mean } \\
6 \cdot 5 \\
6 \cdot 4 \\
0 \cdot 45 \\
28 \\
53 \\
33 \\
115 \\
199\end{array}$ & $\begin{array}{l}S D \\
1 \cdot 1 \\
1 \cdot 1 \\
0 \cdot 04 \\
10 \\
21 \\
15 \\
28 \\
69\end{array}$ \\
\hline
\end{tabular}

*Values for $\mathrm{FEV}_{1}, \mathrm{FVC}, \mathrm{FEV}_{1} / \mathrm{FVC}, \mathrm{TLC}$, and RV exclude the two patients with fibrosing alveolitis.

$\mathrm{PaO}_{2}$ - arterial oxygen tension; $\mathrm{PaCO}_{2}$-arterial carbon dioxide tension (with air); $\mathrm{FEV}_{1}$ - forced expiratory volume in one second; FVC-forced vital capacity; TLC-total lun capacity; RV-residual volume.
Table 2 Complications of transtracheal oxygen therapy in the 37 patients

\begin{tabular}{lc}
\hline Complication & $\begin{array}{l}\text { No of episodes in } \\
595 \text { patient-months }\end{array}$ \\
\hline Surgical emphysema & 10 \\
$\quad$ Cervical only & 8 \\
$\quad$ Including face & 2 \\
Catheter fracture & 9 \\
Partial & 6 \\
$\quad$ Complete & 3 \\
Local infection & 34 \\
Dislodgement requiring catheter & 21 \\
$\quad$ resiting & 1 \\
Sputum plug & 1 \\
Cephaloversion & \\
Others & \\
$\quad$ Streak haemoptysis, blockage, & \\
$\quad$ kinking, cough $\dagger$ & \\
\hline Redness, swelling, or discharge with or without local \\
tenderness. \\
$\dagger$ Infrequent-precise number not recorded.
\end{tabular}

†Infrequent-precise number not recorded.

though one (associated with a partial catheter fracture) occurred at seven days. Surgical emphysema did not impair ventilation and it resolved in all instances after disconnection of the oxygen source from the transtracheal catheter. Two episodes followed a change of catheter with a previously established tract. One case followed replacement of a catheter by the patient after accidental dislodgement at home.

Two of the completely fractured catheters required bronchoscopy for their removal (one fibreoptic, one rigid), but there were no serious sequelae. Infections occurred on 34 occasions but were usually minor and rapidly responded to oral antibiotics. In most culture positive episodes of infection the organism was Staphylococcus aureus. Two patients had colonisation of sputum with Pseudomonas sp, associated with repeatedly positive catheter tip cultures with the same organism. Two patients had persistent local infection with methicillin resistant Staphylococcus aureus and had to return to oxygen therapy via nasal cannulas.

Minor (streak) haemoptysis occurred occasionally in the first few days after a change or insertion of catheter. Two patients had more persistent haemoptysis and underwent fibreoptic bronchoscopy. No malignant lesions were found. Both had small areas of abrasion on the posterior tracheal wall adjacent to the catheter tip.

Increased cough shortly after transtracheal catheter insertion usually settled spontaneously, but in one case was associated with cephaloversion of the catheter. One patient using a catheter of experimental design had a brief but frightening episode of respiratory distress that resolved after he managed to expectorate a sputum plug, which we believe might have accumulated on the catheter tip.

Ten patients $(27 \%)$ are known to have discontinued transtracheal oxygen therapy before death, five within the first six weeks (table 3). One patient had been accepted on the waiting list for heart-lung transplantation and the transtracheal catheter was removed to eliminate a possible source of infection. Two patients elected not to continue with transtracheal 
Table 3 Reasons for discontinuing transtracheal oxygen therapy before death

\begin{tabular}{lll}
\hline & $n$ & $\begin{array}{l}\text { Months of } \\
\text { transtracheal } \\
\text { treatment } \\
\text { (mean } \\
\text { (range) }\end{array}$ \\
\hline $\begin{array}{l}\text { Medically directed } \\
\text { Local infection with methicillin } \\
\text { resistant Staphylococcus aureus }\end{array}$ & 2 & $10(2-19)$ \\
$\begin{array}{l}\text { Dementia } \\
\text { Awaiting heart-lung transplant }\end{array}$ & 1 & $3 \cdot 5$ \\
$\begin{array}{l}\text { Patient directed } \\
\text { Catheter fracture }\end{array}$ & 11 \\
$\begin{array}{l}\text { Surgical emphysema } \\
\text { No clear reason given }\end{array}$ & 1 & $<1$ \\
\hline & 1 & $<1$ \\
\hline
\end{tabular}

therapy because of complications shortly after insertion.

\section{Discussion}

Transtracheal delivery of oxygen has several advantages over conventional delivery with nasal cannulas. The possibility of maintaining a similar arterial oxygen tension with half the flow rate means that portable oxygen cylinders can be used without being refilled for double the time. Patients dependent on oxygen may therefore be able to spend longer periods away from their homes. One of our patients was able to return to work with his transtracheal oxygen system. In addition, transtracheal delivery of oxygen may enable some patients with refractory hypoxaemia to achieve a satisfactory resting $\mathrm{PaO}_{2}$ with an oxygen concentrator.

Transtracheal oxygen may improve compliance with long term domiciliary oxygen therapy and so increase the number of hours a day that oxygen is received. It is easy to use away from home with a portable oxygen delivery system and is easily concealed with a neck scarf. The problem of nasal discomfort is avoided and the catheter need not be removed during daily activities such as washing.

Transtracheal oxygen therapy can be used for long periods without major problems. Patients should be advised that if they develop surgical emphysema they should disconnect their catheter from the oxygen supply immediately, return to using nasal cannulas, and seek medical advice. We advocate routine replacement of catheters every two months to reduce the risk of mechanical deterioration and catheter fracture. This is often performed by the general practitioner. Patients are advised to flush their catheters four times daily to help avoid blockage. Infections should be treated promptly with oral antibiotics. Haemoptysis is usually benign and self limiting, but as lung neoplasms are not uncommon in this group of patients persistent haemoptysis should not be disregarded. Persistent cough associated with a catheter may indicate malposition or cephaloversion. Sputum plugs have been a problem with wider gauge catheters with multiple side vents ${ }^{891216}$ but have not caused difficulties in our experience of using the Angiocath.
Our patients reported benefit from transtracheal oxygen. Patients previously stabilised with nasal oxygen show a further reduction in packed cell volume, ${ }^{69}$ possibly because of improved compliance. By reducing inspired minute ventilation transtracheal oxygen may reduce the work of breathing and so reduce symptoms of breathlessness. ${ }^{17}$ Improvements in mobility and quality of life are likely to influence patients' perceptions of their symptoms. ${ }^{6}$ In addition, there may be a placebo effect, and increased contact with medical personnel may result in additional treatment not directly related to the transtracheal system.

Other devices for oxygen conservation have been described. Other transtracheal systems include the SCOOP method, ${ }^{9}$ in which the use of a stent during tract maturation may reduce the risk of surgical emphysema. The wider gauge catheter with side vents used in SCOOP, however, may predispose to mucus plug formation. ${ }^{7}$ For intratracheal oxygen delivery polymer tubing is tunnelled beneath the skin, producing a totally implanted system. ${ }^{18}$ Our method has the advantages of simplicity and immediate accessibility of the parts for inspection or replacement, and it is easily reversed should the patient not find it satisfactory. Other oxygen conserving devices, such as oxygen pendants, do not avoid the cosmetic problems of nasal cannulas. One study of an oxygen pendant found a drop out rate of $43 \%$ over one month. ${ }^{19}$

Transtracheal oxygen therapy should be considered for two groups of patients who satisfy accepted criteria for continuous domiciliary oxygen therapy ${ }^{3}$ - firstly, patients who do not achieve a $\mathrm{PaO}_{2}$ at rest of at least 8 $\mathrm{kPa}$ despite using maximal flow rates of oxygen from a concentrator via nasal cannulas and, secondly, patients who remain fit apart from their lung disease and are well motivated and keen to pursue an active life outside their homes, but are prevented from doing so by their requirements for portable oxygen.

1 Medical Research Council Working Party. Long term domiciliary oxygen therapy in chronic hypoxic cor pulmonale complicating chronic bronchitis and emphysema. Lancet 1981;ii:681-5.

2 Nocturnal Oxygen Therapy Trial Group. Continuous or nocturnal oxygen therapy in hypoxemic chronic obstructive lung disease. Ann Intern Med 1980;93:391-8.

3 Williams BT, Nicholl JP. Prevalence of hypoxaemic chronic obstructive lung disease with reference to long-term oxygen therapy. Lancet 1985;ii:369-72.

4 Waterhouse JC, Howard P. Breathlessness and portable oxygen in chronic obstructive airways disease. Thorax 1983;38:302-6.

5 Krop HD, Block AJ, Cohen E. Neuropsychologic effects of continuous oxygen therapy in chronic obstructive pulmonary disease. Chest 1973;64:317-22.

6 Bloom BS, Daniel JM, Wiseman M, Knorr RS, Cebul R Kissick WL. Transtracheal oxygen delivery and patients with chronic obstructive pulmonary disease. Respir Med 1989;83:281-8.

7 Heimlich HJ, Carr GC. The Micro-Trach. A seven-year experience with transtracheal oxygen therapy. Chest 1989 ; 95:1008-12.

8 Leger P, Bedicam J-M, Rabiers B, Gerard M, Robert D Oxygenotherapie de longue duree par catheter transtracheal. Agressologie 1988;29:595-602.

9 Christopher KL, Spofford BT, Petrun MD, McCarty DC Goodman JR, Petty TL. A Program for tranty DC oxygen delivery. Ann Intern Med 1987;107:802-8.

10 Banner NR, Govan JR. Long term transtracheal oxygen delivery through microcatheter in patients with hypoxaemia due to chronic obstructive airways disease. $\mathrm{Br}$ Med aemia due to chronic 
11 Hoffman LA, Dauber JH, Ferson PF, Openbrier DR, Zullo TG. Patient response to transtracheal oxygen delivery. Am Rev Respir Dis 1987;135:153-6.

12 Haggi J, Anderhub HP, Kronauer C, Russi EW. Transtracheale $\mathrm{O}_{2}$-applikation zur sauerstoff-longzeittherapie. Schweiz Med Wochenschr 1988;118:1321-4.

13 Christopher DL, Spofford BT, Brannin PK, Petty TL. Transtracheal oxygen therapy for refractory hypoxaemia. JAMA 1986;256:494-7.

14 Heimlich HJ, Carr GC. Transtracheal catheter technique for pulmonary rehabilitation. Ann Otol Rhinol Laryngol 1985;94:502-4.

15 Quanjer $\mathrm{Ph}$. Standardized lung function testing. Clin Respir
Phys 1983;195(suppl 5):45-51.

16 Fletcher EC, Nickeson D, Costarangos-Galarza C. Endotracheal mass resulting from a transtracheal oxygen catheter. Chest 1988;93:438-9.

17 Couser JI, Make BJ. Transtracheal oxygen decreases inspired minute ventilation. Am Rev Respir Dis 1989; 139:627-31.

18 Johnson LP, Cary JM. The implanted intratracheal oxygen catheter. Surg Gynecol Obst 1987;165:75-6.

19 Claiborne RA, Paynter DE, Dutt AK, Rowlands JW. Evaluation of the use of an oxygen conservation device in long-term oxygen therapy. Am Rev Respir Dis 1987; 136:1095-8.

\section{BOOK NOTICES}

The Role of Inflammatory Processes in Airway Hyperresponsiveness. S $T$ Holgate. (Pp 255; £39.50.) Oxford: Blackwell, 1989. ISBN 0-632-02618-

This book is the outcome of a meeting, in Florida in 1988, of a select group of academics and research workers with an interest in the pathophysiology of asthma. The work is divided into seven chapters, though they are really sections, under the headings of: clinical presentation, pathology, diagnostic procedures, physiology, cellular mechanisms, pharmacology and therapeutics, and epidemiology. Each section is composed of contributions from three to five different authors, who obviously bring their own particular interests and slant. That leads to a rather disjointed collection of essays, which at times only loosely fit under the general chapter heading. There is also much overlap between the chapters, and sometimes even repetition within a chapter. Some experimental areas are reviewed several times. I think it would have been better, and more readable, if each author had been given a specific title and chapter within general section areas. That would also have allowed a more detailed contents list, so that a "browser" could accurately select out a focal area of interest. The book contains a number of "gems", which are picked up only by a fairly comprehensive read. One problem with a book based on proceedings of a conference that included presentation of original data is that by the time the book is published the relevant papers have frequently been in the journals for some time, and what was presented as new and hot news at the meeting seems slightly dated by the time the book appears. The book is rather more up market than many such symposium reports, but does suffer to some extent from that inevitable malaise. The title of the book reveals one of its difficulties. It would seem to take the relation between asthmatic airway hyperresponsiveness and airway inflammation as an established truth. Some of the authors do indeed treat the matter as a dogma to be supported, but the better chapters and authors keep a healthier distance and treat the title phrase as a hypothesis to be tested. This variation in approach, rather randomly placed through the book, gives the book a mildly schizophrenic feel when read from cover to cover. Overall, however, this book is a success and deserves a wide readership. It is most appropriate to those with an active research interest and for them the extensive reference lists will be very helpful; but it would also make a useful addition to most hospital libraries, and should certainly be available to departments of chest medicine and to those contemplating studies in this important area.-EHW

Pocket Consultant Respiratory Medicine. 2nd ed. N McI Johnson. (Pp 391; £13.95.) Oxford: Blackwell, 1990. ISBN 0-632-02572-7.

The pace of change in respiratory medicine is illustrated by the necessity for a second edition of this small textbook only four years after the first. The book is aimed at medical students, junior medical staff, physiotherapists, and nurses. About half of the text consists of lists and tables that will be useful to candidates for final and MRCP examinations but casual readers may find them annoying, especially as they are unreferenced. The layout is generally clear but the list of contents contains only seven chapter headings; the reader must then refer to a subindex at the beginning of each chapter. The book contains 136 figures, including 83 chest radiographs and 19 computed tomograms. These are generally of good quality and well chosen to give the beginner a flavour of the most common radiographic abnormalities. Not all of the illustrations are of such high quality-for example, there is a very poor quality illustration of "positive allergy skin prick tests" and the publishers have managed to produce an upside down photograph of a Volumatic spacer device which might confuse the uninitiated. The topics covered are of importance to the target audience but one might expect a mention of primary pulmonary hypertension or the treatment of empyema in a text of this size. Churg-Strauss syndrome and Wegener's granulomatosis appear on a list but are neither indexed nor described. Lung infections are well described, however, with a particularly useful section on AIDS. As with any single author book, the text is sometimes idiosyncratic (nedocromil is preferred to inhaled corticosteroids in adult atopic asthma, and a bronchitic patient, it is said, should be given a trial of steroids only if he or she "might be a chronic asthmatic"). The text is sometimes very topical (HIV infection, methotrexate in asthma) and sometimes quite old fashioned: "intravenous aminophylline is the drug of choice in severe acute asthma attacks," percussive physiotherapy is recommended for acute pneumonia, and diphosphonates are not mentioned in the treatment of malignant hypercalcaemia. In summary, this book will be useful to its intended audience, the chest unit library should contain a copy, and many house officers may wish to buy it themselves.-BR O'D

\section{NOTICES}

\section{International symposia in Rotterdam}

The Eleventh International Symposium on Information Technology in Anaesthesia, Intensive Care, and Cardiopulmonary Medicine will be held in Rotterdam on 8-10 October 1990, and the Sixth International Symposium on Cardiopulmonary Urgencies and Emergencies on 26-29 November 1990. Details may be obtained from Dr Omar Prakash, Thorax Centre, Erasmus University, 3000 DR Rotterdam, The Netherlands (fax 31-10-463-5240).

\section{Drug delivery to the lungs}

A repeat of the meeting on drug delivery to the lungs, held by the Aerosol Society last October, will take place on 4 December 1990 at Fisons PLC, Loughborough. Details may be obtained from Dr S P Newman, Department of Thoracic Medicine, Royal Free Hospital, London NW3 2QG (071 794 0500). 